\title{
La antropología en el país de los equívocos: sutilezas políticas entre los Yánesha de la Amazonía peruana.
}

\author{
André Narro
}

\section{Resumen}

Caja de pandora para muchos, el campo político de los pueblos indígenas sigue despertando sorpresas, seguidas de conclusiones apresuradas, en los medios de comunicación e, incluso, en espacios académicos. Tratando de dar contenido a las estructuras y forma a las experiencias de los líderes del pueblo Yánesha, el itinerario de esta crónica parte de las sutilezas de las prácticas que informan este campo para seguir su desarrollo a través de diversas paradojas. Esto, a través de la narración de los tres días de octubre del 2016 en los que tuvo lugar el Congreso Extraordinario de la Federación de Comunidades Nativas Yánesha.

\section{Palabras clave}

Política, Amazonía, indígenas, Yánesha 


\title{
Anthropology in the land of equivocations: Peruvian subtleties among the Yánesha of the Peruvian Amazon
}

\author{
- André Narro
}

\begin{abstract}
Pandoras's box for many, indigenous peoples' political field continues to arouse surprises, followed by hasty conclusions by the media and even in academic circles. Trying to give content to the structures and form to the experiences of the Yanesha leaders, the itinerary of this chronicle begins with the subtleties of the practices that inform this field, then, to follow its development through diverse paradoxes. All this, through the account of the three days of October of 2016, during which the Extraordinary Congress of the Federation of Yanesha Native Communities took place.
\end{abstract}

\section{Keywords}

Politics, Amazonia, indigenous peoples, Yanesha 
He terminado mi tercera taza de masato y, como despertando de un sueño, veo ante mis ojos las 10 horas de viaje resumidas en algunos vagos recuerdos. La hora de salida, 10 de la mañana, desde Oxapampa, junto con 6 representantes de Tsachopen, comunidad donde pasé la mayor parte de los últimos 3 meses. Una breve parada en Villa Rica, luego de atravesar el bosque de Sho'llets, para recoger a los jefes de comunidades cercanas. Durante 4 horas, el paisaje, conforme nos adentramos al noreste, tomará cada vez un tono más tupido de verde; el río Cacazú, lentamente, impondrá su voz, acompañado de cantos cada vez más prominentes de aves. Algunos jefes que he conocido durante mi estancia subirán a la tolva del carro cuando este pase por cada una de sus comunidades, divididas siempre por la carretera. En un punto de la selva, los senderos se bifurcan: un camino anuncia el inicio del distrito de Palcazú, creado en 1986, mientras que, el otro, se dirige a Puerto Bermúdez, Constitución y eventualmente a Pucallpa. Tomando el segundo, una hora más por las alturas de San Matías, desde el mirador se aprecia la infinita masa de tonos de verde, copas de árboles como un mar de nubes extendiéndose hasta donde la vista llega. “Es bello, ¿no, Andre?”, me pregunta Coñehuo trayéndome de vuelta al hecho de que estábamos camino al congreso extraordinario de la Federación de Comunidades Nativas Yánesha (FECONAYA). Comienza un distendido descenso por San Matías que de golpe une este recuerdo mío con otro mucho más antiguo. La carretera ya no es de tierra afirmada sino que el color de esta pasa a ser más rojizo y su compactado más ligero revelando su juventud. La vía se ancha hasta llegar a un máximo de 10 metros, a cuyo final inicia una cadena tupida de árboles. Las máquinas siguen trabajando incesantemente en este tramo de un sueño, o pesadilla como dirían muchos yánesha, iniciado hacia 1959. Recuerdo que la carretera a la salida de Villa Rica lleva el nombre del autor que soñó esto que ahora recuerdo y que es parte de la vida cotidiana de los yáneshas y asháninkas desde la década de 1980. La memoria de Fernando Belaúnde Terry y el Proyecto Especial Pichis-Palcazú (PEPP) toma forma en esas máquinas, en esas luces, en esas personas que trabajan día y noche a lo largo de más de una centena de kilómetros para unir, finalmente, Lima con Pucallpa, pasando por la Selva Central y Constitución ${ }^{1}$, a través de la Carretera Marginal.

Cortando este retorno, curiosamente es el silencio el que llama mi atención ya que hasta hace algunos segundos las risas y las conversaciones entre jefes y jefas constituían el ambiente. Han llegado los jefes de la zona baja del río Palcazú, donde se concentra gran parte de la población yánesha. Camino por río y luego en carro desde Constitución, son los últimos en llegar. Para mi sorpresa, alrededor de la banca donde los delegados de Tsachopen y yo descansábamos se había formado un círculo. Dentro de los hombres recién llegados, uno recibía todos los saludos respetuosos de los demás jefes. Solo mis compañeros de Tsachopen fueron efusivos en su alegría pues para ellos este era un amigo que no ven ya con regularidad. Polo piqué rosa con cuello, bermudas cargo, botas de goma y una pequeña mochila a la espalda eran toda la indumentaria de este hombre de alrededor de 60 años cuyo nombre yo había leído repetidas veces las semanas anteriores en documentos emitidos durante su gestión

1. Ciudad soñada y fundada en el año de 1984, durante el segundo gobierno de Belaúnde, bajo el nombre de Ciudad Constitución. 
como Kornesha, presidente de FECONAYA, entre los años 2009 y 2012, y cuya mirada escrutaba la escena. Como era de esperarse, preguntó por la presencia del Kornesha. Paco, hombre de Tsachopen respetado por su conocimiento de los cuentos de los abuelos y las plantas medicinales, dice que ha salido al último de Oxapampa trayendo la comida y documentos; viene en un carro de la municipalidad provincial y seguramente no tarda en llegar. Con un gesto de sorpresa y leve disgusto, Jicho replica: "Debemos salir todos juntos en convoy. Así si pasa lo del último congreso nadie se queda botado a su suerte. Debemos salir unidos y volver unidos”. Pregunta nuevamente, ahora sobre la cena y si todos tienen alojamiento ya. Al escuchar que hay atún y que se han acomodado en casas de yáneshas que no sabían que llegarían o no lo recordaban, Jicho vuelve a expresar su descontento; primero, sarcásticamente evidencia la paradoja de que en una zona donde los ríos están tan cerca no haya pescado y, luego, diciendo que antes en los congresos toda la comunidad se organizaba, no solo unas cuantas mamás, como las que ve ahora haciéndose cargo. La presencia del antropólogo no pasa inadvertida y rápida pero cortésmente soy interrogado por mi identidad. Interesado sobre las transformaciones de lo político en el pueblo Yánesha, respondo que investigo la historia de la FECONAYA. Escucho a Jicho decir que la comunidad está sobre antiguas oficinas del PEPP y, en tono de broma, me repregunta si pertenezco a la CIA o para cuál gobierno trabajo: “¿Cómo? ¿Antropólogo y no sabes esas cosas?”. Primera advertencia para un antropólogo en campo: siento que obtengo el reflejo de lo que soy, un producto de lo que los yánesha llaman Occidente.

En ese mismo instante un carro se detiene y baja el Kornesha. Tiene menos de 35 años, licenciado en Educación, hombre robusto y directo, también jefe saliente de Tsachopen. Saludando alegremente a los jefes que se encontraban en la periferia del círculo, extiende un saludo primero a Jicho, quien también es el hermano de su madre. Luego, de estrechar la mano de cada uno de los presentes, todos hombres, pregunta si ya cenaron. Todos dicen que sí, salvo los recién llegados. Luego de beber el masato alcanzado, pide disculpas por la desorganización debida a que el jefe de la asociación está en Constitución haciendo gestiones para la alimentación y su aniversario, que será el domingo, mismo día que termina el congreso. Promete mañana estará todo en orden e invita a los jefes recién llegados a cenar para luego ir a Constitución donde se alojarán esta noche. Desea buenas noches a los presentes recomendándoles dormir temprano y se retira a coordinar detalles. Antes de pasar a dormir, contemplo la escena. Bajo el techo de calamina que se extiende desde un lado de la casa donde descansan delegadas y jefas, dos tablas de madera hacen de bancas y acompañadas de un tacho de masato junto a una piragua llena de masa de yuka componen el comedor donde los hombres siguen bebiendo. Entre este y el salón comunal tendrán lugar los eventos que darán luz a algunos elementos de la política entre los yánesha.

\section{I}

Todo comienza antes de las 6 de la mañana, cuando el calor de octubre impide seguir durmiendo e impone un baño, ya sea en los espacios donde están los pozos de agua de cada casa o en el río Pichis a menos de 5 minutos de la asociación. De vuelta al comedor, los jefes y jefas hacen fila para recibir la avena con galletas. Algunos ya se 
prestan a tomar masato. En medio de las conversaciones tímidas de jefes nuevos y otras más distendidas entre antiguos dirigentes, aparece el Kornesha quien saluda alegremente a todos. Pasa por cada grupo y entre bromas y palmadas en la espalda, desea buena mañana. Al llegar al extremo del comedor, dice en voz alta: "Buenos días, jefes, jefas. Voy a ver el local. Ustedes sigan desayunando. Los que quieran pueden acompañarme”. Sin decir una palabra, Paco, Coñehuo y un hombre más seguimos al Kornesha por la pista. A dos cuadras se encuentra el local comunal. "Hace falta una barrida, ¿no?”, frase del Kornesha ante la cual los 3 hombres se aproximan a un árbol cercano y arrancando algunas ramas arman escobas con las que comenzamos a barrer el piso de cemento del local. El Kornesha busca los cables del equipo de sonido que ya se encontraba allí y pone Juaneco, seguido de koshamñats ${ }^{2}$. Concentrado en mi labor no me percato que ya no somos 5 sino muchos más; aparecen las sillas y las mesas. "André, esto es la FECONAYA y el trabajo yánesha”, ilustra el Kornesha. En menos de 20 minutos el local luce un rostro ordenado; como en un mismo movimiento, aparecen las coronas con sus largas plumas de colores, las cushmas de algodón con diferentes tonos de rayas alternando sobre un fondo blanco o hueso. Llegan las jefas con cushmas de tela tocuyo de variados colores, adornos largos de semillas rojas y negras.

Escena llamativa por el hecho que ninguna orden haya sido dada por nadie; todo desencadena por la invitación y primera acción del Kornesha. Pienso, al igual que Brown (1993), ¿no se compone también de este tipo de sutilezas el campo político del pueblo yánesha y de muchos pueblos indígenas? No hay tiempo ni espacio para continuar estas meditaciones pues el ambiente es invadido por yeñoño, "nuestras palabras". Y es que cuando ya todos están dispuestos en sus lugares, el primer Kornesha del Congreso Amuesha ${ }^{3}$ aparece por medio de una grabación de más de 40 años de antigüedad. Rememorando al primer yánesha que, sin saber leer o escribir, ingresó a Palacio de Gobierno en Lima para hablar de "jefe a jefe" con el Presidente de la República, comienza el congreso extraordinario con 47 años de existencia detrás.

\section{II}

Como ya había señalado Smith (1981), los yánesha fueron y son un pueblo sumamente religioso. Por ello es imposible iniciar el congreso sin comunicarse con Yompor por medio de una oración, a cargo de Paco. Enigma todavía para mí pues sé bien que Yompor significa "nuestro padre" y designaba a una categoría particular de seres, divinidades, dentro de las cuales el más poderoso era Yompor Ror, Nuestro Padre Sol; referencia que cambió hacia inicios de 1980 gracias al trabajo del Instituto Lingüístico de Verano, quienes por medio de los profesores bilingües que formaban difundieron la religión cristiana y la idea de Dios como Yompor (Smith, 1981). Determinar la identidad y formas de relación con Yompor es otra historia. Lo importante es que todas las mañanas se repetirá la oración seguida de la música de carrizos y la danza y canto de mujeres, también dedicadas a Yompor y al Kornesha.

2. Este término engloba, en diferentes niveles de exclusividad, un tipo de música yánesha (Smith, 1977).

3. Etnónimo dado a los yánesha hasta 1980, año en que reclaman llamarse y ser llamados de esta última manera. 
La inauguración debe ser más corta que de costumbre debido a que desde la mañana acompañan 4 invitados del Estado peruano. Las visitas de las instituciones se reservan siempre para el último día, según me cuentan, pero se comprende la presencia temprana del Ministerio de Cultura y la Defensoría del Pueblo ya que hace menos de un mes una anciana asháninka ha sido quemada en una comunidad yánesha luego de 20 años de acusaciones de brujería. Hecho que, según mis anfitriones, podría pasar desapercibido si no fuera porque un externo grabó el evento y lo subió a internet desatando los antiguos, e infundados, comentarios sobre el "salvajismo" de los yánesha a nivel nacional e internacional.

El primero en hablar es un awajún de alrededor de 30 años que lleva el famoso apellido Nugkuag. Los presentes se alegran de que el Estado envíe un indígena para conversar. "La historia sigue, avanza", frase del mismo Nugkuag que podría servir de hilo en su explicación del paso de los reductores de cabezas a los líderes políticos de "flechas de ideas" de los awajún contemporáneos, de la asistencia cada vez mayor pero aún insuficiente y deficiente del sistema de salud peruano en detrimento de las plantas medicinales y los iwishín, chamanes entre los awajún. Como si fuese obra del calor en aumento, la alegría inicial evanesce entre los yánesha al entender que aquel indígena no apoya del todo su postura. Continúa una joven abogada de la Defensoría del Pueblo. Descripción del marco legal nacional e internacional que brinda derechos a los indígenas proclamando su autonomía siempre y cuando no se vulneren derechos humanos. Si la alegría había desaparecido, nace la incomodidad en ese mismo lugar. Los ceños se fruncen y los murmullos proliferan; nada nuevo ha sido dicho a los jefes y jefas y, por si no fuera poco, una vez más se ha levantado la pared entre el Estado occidental y una cosmovisión indígena. La primera en tomar la palabra es una dirigente de la comunidad donde se quemó a la mujer. Ella misma escuchó a esta última admitir haber comido a su madre por dentro durante meses. Testimonio emotivo que defiende las acciones de la comunidad aun así le cueste la cárcel. Para cerrar, pregunta por qué una vez sancionado el delito el Estado acude si cuando solicitan la intervención de las autoridades alegan que son autónomos de acuerdo a sus normas, es decir sus estatutos. Sigue un antiguo dirigente, fundador de la FECONAYA, migrante andino. "Para los pueblos originarios no existen derechos humanos", frase que tendrá eco en las palabras de otros. "El violador, el asesino, el que sigue a pesar de las advertencias, solo a ese lo revertimos a la tierra. Para nosotros es abuso a la naturaleza y lo damos como ofrenda”, alega haciendo referencia al largo proceso de sanciones que practican los yánesha. Sin embargo, es un discurso particularmente llamativo pues nunca leí o escuché algo así entre los yánesha. Como dijo un jefe ese mismo día, se le quema para que su espíritu malo no regrese y cutipe a las personas de la comunidad. Además, la mujer trabajaba con ayahuasca, planta que para muchos yánesha tiene una intencionalidad intrínsecamente mala pues solo enseña a hacer el mal. El Kornesha dice que esto es "un tema cultural” y así hay que entenderlo. Jicho señala que la historia avanza pero les da fuerza: los antiguos kornesha ya sabían quién era malo a través de la coca y cuando estos llegaban a las reuniones nada más los eliminaban. Es la disciplina de los abuelos que debe ser respetada y cuidada.

Al final del congreso, en el memorial se argumenta que la quema de la mujer fue siguiendo las "leyes ancestrales" de los yánesha y que por "abuso a la naturaleza" 
se la dio como ofrenda.¿Por qué acoger este discurso en vez de explicar la cutipa, la moral yánesha, la memoria de los kornesha? ¿Por qué no decir que Axhkash, el dirigente andino, está equivocado, como lo hicieron luego en el almuerzo? Creo que el documento mismo brinda la respuesta. Dirigido al Presidente, a los Ministerios y a los medios, el documento emplea un lenguaje técnico y una justificación ajena a la perspectiva de los yánesha. Creo, es el reflejo de la lengua del Otro pero también es un arma de los yánesha. Desprestigiar a Axhkash es mostrar fisuras en la FECONAYA y retar su propia unidad. Cuestión desfavorable cuando el que está al frente y con quien se quiere negociar es el Estado. Por ello quizá hablen la lengua del Otro para finalmente hacerlo hablar como yánesha. Y en ese camino, sea necesario traducir su cosmovisión a algo que los ocanesha ${ }^{4}$ puedan entender sin necesariamente

\section{III}

Un poco tarde me encuentro en el desayuno con un círculo de dirigentes tomando masato. Preparando el terreno para el debate sobre el cargo de Kornesha en la reforma estatutaria emprendida hace un año, Mayarr, Kornesha interino entre los años 2005 y 2006, se une al grupo bromeando que él puede ser Kornesha en su palacio y tener 5 collas. Lina le pregunta qué haría ese kornesha, “¿tabaquear todo el día?”. Entre risas se esclarece que hay una posibilidad de que el kornesha sea interno y tenga su templo donde recupere la cultura, y el presidente sea "más de hacer gestión". Nadie sabe bien qué resultará pero coinciden en que debe quedar en claro en el Estatuto.

La sesión que comienza con la resolución de un problema de desaparición de equipos y dinero donados por La Petrolífera para la instalación de una radio en Iscozacín, Palcazú, durante gestión del kornesha antecesor, culmina con un debate de la unidad y el papel de la FECONAYA. Durante estos meses la frase "La FECONAYA es papá del pueblo yánesha" o "Usted, Kornesha, como padre de las comunidades nativas..." me resultaba sumamente enigmática. Sintiendo que no se trataba de un recurso de la poética yánesha, me rehusaba a no tomar en serio lo que la gente me decía. Finalmente, este día, que la frase fue repetida hasta el cansancio, pude aproximarme a su comprensión. Recordando que las divinidades se organizan de acuerdo a una lógica de parentesco en la cual los de categorías mayores son padres directos de los siguientes, donde los yánesha son hijos de Yompor Ror (Santos Granero, 1994; Smith, 1977), y tomando en cuenta que se llamaba a los antiguos kornesha como nompor, "hermano de nuestro padre", y este llamaba a sus seguidores, pueyochresha", "hijos de mis hermanos", se tiene que las relaciones de poder al interior del pueblo yánesha se inscriben en una lógica análoga a la relación de padre e hijo (Santos Granero, 1994). Habida cuenta del retroceso en el uso de la lengua nativa y auge del castellano, el hecho de llamar padre a la FECONAYA y al Kornesha no sería más que una reducción de la traducción del concepto relacional yánesha al castellano. La idea cobra mayor fuerza si se toma en cuenta que para muchos colectivos indígenas la relación de paternidad

4. Término que designa a los blancos y mestizos.

5. Tanto nompor como pueyochresha se usan cuando el hablante es masculino; nepapar y posñenesha, respectivamente, para hablante femenino. 
es una relación de domesticación, "una disposición acumulativa y compartida" (Surrallés, 2009, p. 71). Momento ideal para el recuerdo de las historias de vida de los dos primeros Kornesha del Congreso Amuesha quienes, incluso antes de la Ley de Comunidades Nativas de 1974, recorrieron a pie todo el territorio yánesha y también asháninka del Pichis, creando y produciendo comunidades con amcha'taret, jefes, y resolviendo problemas de rebeldes e invasores; es decir, ejerciendo justicia de acuerdo a su ethos. Además, eran ellos, junto con los primeros amcha'taret, quienes intervenían ante el Estado para llevar títulos, escuelas, postas, caminos, donaciones y demás atenciones a los asentamientos. Las categorías de parentesco sirven para designar relaciones y actitudes entre sujetos antes que nada (Gow, 1991); si esto es cierto, padres de familia, amcha'taret, korneshas y FECONAYA seguirían una lógica analógica resaltando el hecho que el liderazgo no se crea de una vez y para siempre, así lo diga su ley, sino que debe ser producido y reproducido en la interacción y acción. De esto que las comunidades reclamen que el Kornesha las visite y no las deje en la ausencia de su líder máximo, como solicitan los jefes durante el congreso.

Tomando la anécdota de la radio, el Kornesha recuerda que durante aquella gestión la FECONAYA vivió una fuerte división. Un kornesha, elegido rompiendo las normas del estatuto pues no había sido jefe, se apropió de cerca de 20 ooo soles; al ser destituido y nombrado aquel que tuvo el problema de la radio, el primero emprendió juicios impidiendo que la FECONAYA se inscriba en Registros Públicos. Luego de un año de gestión del actual Kornesha, y 4 de caos, por fin pudo lograr la inscripción y recuperar las vías para que FECONAYA obtenga donaciones, recupere confianza de aliados y con ello proyectos para las comunidades, y vuelva a ser una. La alegría recupera los cuerpos de los jefes quienes aplauden. Se saluda el regreso del orden. Se invita a seguir en unidad. Jicho dice que FECONAYA es padre de la Unión de Naciones Asháninka Yánesha (UNAY), de la Asociación de Nacionalidades Asháninkas del Valle Pichis (ANAP) e incluso de la Confederación de Nacionalidades Amazónicas del Perú (CONAP) porque los jefes que las fundaron se formaron en aquella y estos reconocen a FECONAYA como padre pues esta nunca dejó de cuidarlos ni se negó a apoyarlos. Para evitar que se repita este cataclismo, su ley, su Estatuto, debe ser fuerte, lo que da pie al debate de qué es un kornesha. Todos concuerdan en que es la autoridad máxima del pueblo yánesha; sin embargo, la antropóloga que los asiste en la elaboración del estatuto dice que la asamblea es la autoridad máxima de la FECONAYA. A pesar de esta apariencia de paradoja, en efecto hay diversas muestras de que el colectivo, comuneros o asamblea de jefes, es quien determina con su voluntad las acciones y los jefes o Kornesha deben tener la suficiente habilidad de leer esas voluntades, conciliarlas y transformarlas en acciones, incluso cuando él discrepe, pues la imposición de su voluntad le costaría el rol asignado; inevitables meditaciones clastreanas durante el congreso.

El ritmo no aminora y una delegada de Tsachopen alza la voz de las mujeres: ellas merecen ser Kornesha. Los antecedentes retroceden al 2003 cuando ella promueve, siguiendo la lucha de mujeres mayores, el voto femenino en congresos. Es hora de que ellas puedan ser presidentas pues han demostrado ser excelentes jefas. La antropóloga saluda la intervención y propone llamar "Presidenta" de ser electa una mujer y "Presidente - Kornesha" de ganar un hombre. En honor al "factor cultural" no pueden debilitar al pueblo así; los abuelos y abuelas lloran cuando les dicen que 
una mujer quiere ser Kornesha diciendo que el mellapo, fin del mundo, está cerca; las mujeres no pueden ser Kornesha por su alta tendencia a dejar a sus familias por aventuras con dirigentes, dicen los hombres, haciendo omisión a que un Kornesha fue retirado del cargo por los mismos motivos. El debate se prolonga hasta que una joven jefa dice que a ella le enseñaron que kornesha solo fueron hombres y que así debe ser por el bien de la FECONAYA. Buena educación y respeto por el pueblo yánesha muestra la joven, según Jicho. Agrega que ellas pueden aspirar a puestos en las municipalidades, alcaldesas, el Congreso de la República y, por qué no, la Presidencia de la República. El jefe de Cartagena determina la solución: que la Secretaría de la Mujer sea elevada a Jefa de las Mujeres - Axh Pallá. Acuerdo general: el Kornesha fue y será hombre; las mujeres tienen una jefa, Axh Pallá, quien estará siempre en coordinación con el Kornesha.

El debate sigue pues un exkornesha sanciona el olvido de lo que fue un kornesha. Aquellos líderes cuya principal función era comunicarse con las divinidades 'Nuestros Abuelos y Nuestros Padres' para mantener el orden entre los yánesha y así recuperar la vida eterna al regreso de Yompor Ror son descritos como "sabio, curandero, médico, científico, etc". "Ya no hay", se escucha entre los murmullos. Este mismo exkornesha desea que el Presidente de FECONAYA siga siendo político pero que haya un kornesha con su poherua, edificio donde celebraba koshamñats en las lunas llenas. Se insiste en que no se debe debilitar culturalmente al Kornesha pues este merece respeto y es el líder de su pueblo. Si bien este ya no tabaquea o tiene un saber cosmológico amplio, es el paradigma del yánesha actual. Si bien ya no es el generoso por antonomasia es el que se mueve a nombre de todos sin necesariamente pedir recursos; si bien ya no debe conocer sin error las composiciones reveladas por las divinidades, sí debe ser un orador privilegiado en yeñoño pero también en castellano, que logre mostrar en sus palabras la fuerza de su pensamiento; para ejercer la justicia ya no basta solamente conocer y ser expresión de la moral ancestral sino disponer del saber jurídico necesario. Hay que innovar mucho para seguir siendo tradicional, dice Latour (2012). Se determinan los requisitos: para ser Kornesha es necesario ser jefe o haberlo sido, tener una trayectoria reconocida como persona y líder, manejar la lengua perfectamente, tener el respaldo de su comunidad por medio de una carta, no tener antecedentes penales ni faltas comunales graves; finalmente, respetar el acuerdo de que la elección de los Kornesha sigue la rotación de acuerdo a las zonas (alta, media, baja). De concluir bien su labor, gozará del prestigio respectivo y pasará a ser parte del Consejo de Sabios, Eñotañare. Esta cuestión es clave porque a pesar de haber vivido grandes transformaciones cosmológicas en menos de un siglo, el pueblo yánesha sigue apreciando el saber y ubicándolo como la fuente del poder de sus líderes y de su colectivo.

\section{IV}

Entre fragmentos de canciones de cumbia y recuerdos de la noche anterior, me pregunto si fue de esta manera que, en 1972, los abuelos y abuelas eligieron llamar Kornesha al líder ${ }^{6}$ de su Congreso. ¿Qué debate se habrá dado entre esas personas que conocieron efectivamente a los kornesha? ¿Qué fragmentos de la historia de 
este pueblo se habrán perdido ya en la noche de los recuerdos? Lejos de alimentar mi nostalgia, aún hoy encuentro una respuesta que muchos, contemporáneos y otros por venir, considerarán un tesoro.

Un exkornesha, quién inscribió oficialmente por primera vez una dirigencia de FECONAYA en 1988, solicita la creación de un cuerpo de seguridad, tal como tienen los asháninka su ejército. "Busquemos un término en yeñoño", dice Jicho. El primero dice que no sea un nombre guerrero para no dar miedo; Coñehuo propone ashalluac traduciéndolo como "el que guarda orden". Otro exkornesha menciona que aquel era el que ponía orden y ejecutaba, "cortaba cabezas". Paco dice que se busque un nombre disciplinario, fuerte y connote orden; intervención apoyada por un jefe que solicita también se retire el sentido violento. Al parecer ashalluac era quien, bajo órdenes de los kornesha, eliminaba los rebeldes; por ello, un jefe lo traduce como sicario despertando la duda entre los presentes. Surgen las alternativas: cuansay, "el que cuida"; arkansh, quien ejecutaba la sanción. Es claro, dice un jefe, hay que consultar a sus científicos, a sus sabios. "Tratamos de rescatar el nombre nada más, no la práctica", dice un jefe como piensa el antropólogo. Finalmente, el traductor oficial reconocido por el Ministerio de Cultura pasa al frente para determinar, provisionalmente, el nombre de la "Seguridad Indígena Yánesha - Achallhuak".

Una vez más, siento que el castellano es la lengua de destino mas no la de partida; y ciertamente el movimiento bien delimitado por el jefe anteriormente, misma palabra-diferente práctica, o mismo significante-diferente significado, como me sentí inclinado a pensar de inicio, creo que abre el camino a un reflexión más de fondo. Me veo frente a un reto digno de los críticos de Pierre Menard, autor del Quijote. En yánesha o castellano lo que veo movilizarse no son solamente palabras o memorias con un contenido definido que el antropólogo debe descifrar: son prácticas, sentidos, relaciones y transformaciones. En otras palabras, se penetra en el corazón de la existencia, la distribución de las propiedades, modos de identificarse y ser que parecen propios de un laboratorio. Sea el control de las acciones de una planta como la ayahuasca y la defensa de los derechos, las competencias de un Kornesha en su colectivo o el orden del pueblo yánesha; sea el tema que sea, en este parlamento están emergiendo órdenes y diferencias, relaciones y formas de ser que moldearán, al igual que durante los últimos 50 años, los caminos del pueblo Yánesha.

6. Durante los primeros años del Congreso Amuesha, el Kornesha era el líder de los Yánesha por sobre el presidente 


\section{BIBLIOGRAFÍA}

Brown, M. (1993).

"Facing the State, Facing the World: Amazonia's Native Leaders and the New Politics of Identity”. L'Homme, (126-128), 307-326.

Gow, P. (1991).

Of mixed blood: Kinship and History in Peruvian Amazonia. New York, United States:

Oxford University Press.

Latour, B. (2012).

Nunca fuimos modernos. Ensayos de antropología simétrica. Buenos Aires, Argentina: Siglo XXI.

Santos-Granero, F. (1994).

El poder del Amor: poder, conocimiento y moralidad entre los Amuesha de la selva central del Perú. Quito, Ecuador: Abya-Yala.

Smith, R. C. (1981).

The Summer Institute of Linguistics: Ethnocide Disguised as a Blessing. En Hvalkof, S. y Aaby, P. (Ed.), Is God an American? An anthropological perspective on the missionary work of the Summer Institute of Linguistics (pp. 120-132). Copenhagen, Dinamarca: IWGIA, Survival International.

Smith, R. C. (1977).

Deliverance from Chaos for a Song: A socialand religious interpretation of the ritual performance of Amuesha music (Tesis doctoral). Cornell University Press, Ithaca.

Surrallés, A. (2009).

En el corazón del sentido: percepción, afectividad y acción en los Candoshi. Lima, Perú: IFEA. 